\title{
Endoglin Mediates Vascular Endothelial Growth Factor-A-Induced Endothelial Cell Activation by Regulating Akt Signaling
}

Pascal Bus, ${ }^{*}$ Tessa Gerrits, ${ }^{*}$ Sharon A.C. Heemskerk, ${ }^{*}$ Malu Zandbergen, ${ }^{*}$ Ron Wolterbeek, ${ }^{\dagger}$ Jan A. Bruijn, ${ }^{*}$ Hans J. Baelde, ${ }^{*}$ and Marion Scharpfenecker*

From the Departments of Pathology* and Medical Statistics and Bioinformatics, ${ }^{\dagger}$ Leiden University Medical Center, Leiden, the Netherlands

\author{
Accepted for publication \\ August 2, 2018. \\ Address correspondence to \\ Pascal Bus, Ph.D., Department of \\ Pathology, Leiden University \\ Medical Center, PO Box 9600 , \\ L1Q, Room P0-107, 2300 RC \\ Leiden, the Netherlands. E-mail: \\ p.bus@lumc.nl.
}

\begin{abstract}
In diabetic nephropathy, differential expression of growth factors leads to vascular changes, including endothelial cell activation, monocyte infiltration, and inflammation. Endoglin plays an important role in endothelial function and is also associated with inflammation. In the kidney, vascular endoglin expression is increased in animal models of renal injury, where it contributes to disease severity, possibly by promoting endothelial cell activation and inflammation. Herein, we investigated whether endoglin expression is associated with diabetic nephropathy. In addition, we examined whether reducing endothelial endoglin expression in vitro affects endothelial cell activation and monocyte adhesion and, if so, which intracellular pathways are involved. Finally, we analyzed whether glomerular endoglin expression is correlated with endothelial cell activation in patients with diabetic nephropathy. Endoglin levels were significantly increased in mice with type 1 diabetes compared with control mice. Reducing endoglin expression in cultured endothelial cells significantly impaired the vascular endothelial growth factor-A-induced up-regulation of activation markers and monocyte adhesion. This was mediated by increased phosphorylation of Akt, thereby inhibiting activating transcription factor 2 phosphorylation, which regulates vascular cell adhesion molecule-1 (VCAM1) gene transcription in these cells. Last, endoglin colocalized with VCAM-1 in the glomeruli of diabetic patients, glomerular VCAM-1 expression was significantly increased in these patients, and this increase in VCAM-1 expression was correlated with increased glomerular endoglin expression. Thus, targeting endoglin function may have therapeutic value in patients at risk for diabetic nephropathy. (Am J Pathol 2018, 188: 2924-2935; https://doi.org/10.1016/j.ajpath.2018.08.005)
\end{abstract}

Diabetic nephropathy develops in $20 \%$ to $40 \%$ of diabetic patients and is the leading cause of end-stage renal disease worldwide. ${ }^{1}$ Diabetic nephropathy is characterized by microvascular injury, resulting from hyperglycemia, high blood pressure, and dyslipidemia; it is associated with increased production of reactive oxygen species, an accumulation of advanced glycation end products, and the activation of intracellular signaling molecules, such as protein kinase C. ${ }^{2}$ As a consequence of these processes, the expression of several growth factors changes-including vascular endothelial growth factor A (VEGF-A) - causing an angiogenic imbalance, ultimately leading to, but not limited to, endothelial dysfunction and activation, ${ }^{3}$ monocyte infiltration, ${ }^{4}$ and inflammation.
Endothelial cell activation is characterized by the increased surface expression of adhesion molecules, such as vascular cell adhesion molecule (VCAM)-1, intercellular adhesion molecule (ICAM)-1, and E-selectin ${ }^{6}$; increased endothelial permeability; and a prothrombotic and proinflammatory phenotype. ${ }^{7}$ VEGFA induces endothelial activation by binding to vascular endothelial growth factor receptor 2 (VEGFR2/KDR), leading to activation and internalization of this receptor and subsequent phosphorylation and activation of extracellular signal-regulated kinases 1 and 2 (ERK1/2). Phosphorylated

Supported by the Department of Pathology at the Leiden University Medical Center.

Disclosures: None declared. 
ERK1/2 translocates to the nucleus and promotes activating transcription factor 2 (ATF-2) phosphorylation, which regulates VCAM1 gene transcription. ${ }^{8}$ Increased expression of VCAM-1 on the endothelial cell surface, in turn, aids in leukocyte extravasation, ${ }^{9}$ ultimately leading to inflammation. A link between VEGF-A-induced endothelial changes and endoglin has been suggested; however, it is currently unknown which mechanism causes this link.

Endoglin is an important molecule involved in physiological and pathologic vascular changes. Studies using endoglindeficient mice showed that endoglin plays an essential role in angiogenesis and vascular remodeling. ${ }^{10,11}$ Under physiological conditions, endoglin is expressed in endothelial cells at relatively low levels; however, endoglin expression increases during angiogenesis ${ }^{12}$ and in response to vascular damage. ${ }^{13}$ Furthermore, the expression of endoglin in endothelial cells increases during inflammation and is associated with the infiltration of inflammatory cells, such as macrophages. ${ }^{14}$

Recently, it has been demonstrated that endoglin colocalizes with VEGFR2 in early endosomes on stimulation with VEGF-A and that endothelial cells with decreased endoglin expression display increased phosphorylation of Akt. ${ }^{15}$ Activation of the Akt pathway has been shown to inhibit adhesion molecule expression after VEGF stimulation, ${ }^{3}$ possibly by reducing the phosphorylation of ATF-2. ${ }^{16}$ Therefore, decreasing the expression of endoglin might reduce VEGF-A-induced endothelial activation and subsequent leukocyte extravasation by increasing the phosphorylation of Akt, thereby down-regulating ATF-2-induced transcription of VCAM1.

Herein, it was investigated whether glomerular endoglin expression is associated with diabetic nephropathy using both mouse and patient samples. Moreover, it was examined whether reducing endothelial endoglin expression affects endothelial activation and/or monocyte adhesion on stimulation with VEGF-A and, if so, which intracellular signaling pathways are involved. Finally, it was studied whether glomerular endoglin expression is correlated with endothelial activation in patients with diabetic nephropathy.

\section{Materials and Methods}

\section{Animal Studies}

All experiments were conducted in accordance with national guidelines for the care and use of experimental animals [Animal Experimental Committee (DEC) license 13163]. The diabetic mouse model used in this study has been described previously. ${ }^{17}$ In brief, diabetes was induced in 8week-old female C57BL/6J mice (obtained from Harlan Laboratories, Indianapolis, IN) by three i.p. injections of streptozotocin $(75 \mathrm{mg} / \mathrm{kg}$ body weight; Sigma-Aldrich, St. Louis, MO) administered at 2-day intervals. Male mice tend to be more susceptible than female mice to streptozotocininduced diabetes (eg, male mice develop more severe hyperglycemia compared with female mice). ${ }^{18}$ However, once diabetes has developed, male and female mice do not differ with respect to albuminuria. ${ }^{19}$ Therefore, only a female mouse was considered to be diabetic when the blood glucose level was $\geq 15 \mathrm{mmol} / \mathrm{L}$. Injecting these female mice with streptozotocin induces diabetic nephropathy, as evidenced by the development of albuminuria, glomerular hypertrophy, and extracellular matrix deposition, as well as increased endothelial activation and inflammatory processes. ${ }^{17}$ Diabetic mice ( $n=10$ per time point) and age-matched nondiabetic control mice ( $n=5$ per time point) were sacrificed at 5 and 15 weeks after the induction of diabetes, and renal tissues were collected, fixed, and embedded in paraffin for immunohistochemical analysis.

\section{Human Kidney Samples}

Renal biopsy samples from 11 patients with histologically confirmed diabetic nephropathy were obtained from the pathology archives of the Leiden University Medical Center (Leiden, the Netherlands). Three of these patients (27\%) had class II diabetic nephropathy, seven (64\%) had class III diabetic nephropathy, and one (9\%) had class IV diabetic nephropathy. As a control group, tumor-free renal resection material obtained from seven patients with impaired renal function who had a tumor elsewhere in the kidney was used; the tissue sections used for staining were morphologically normal. Tissue samples in both groups were not matched for age and sex but were included on the basis of tissue morphology. Clinical data are provided in Supplemental Table S1. All human samples were collected and handled in accordance with Dutch national ethics guidelines (Code of Conduct for Proper Secondary Use of Human Tissue).

\section{Immunohistochemistry}

Sections ( $4 \mu \mathrm{m}$ thick) of paraffin-embedded kidney tissues were cut using a Leica microtome (Wetzlar, Germany). For staining endoglin, sections were subjected to heat-induced antigen retrieval using tris-EDTA $(\mathrm{pH} 9)$ and then stained with goat anti-human endoglin (1:800; R\&D Systems, Minneapolis, MN); this antibody also cross-reacts with mouse endoglin. For staining VCAM-1, sections were subjected to heatinduced antigen retrieval with citrate buffer $(\mathrm{pH} 6)$ and then stained with mouse anti-human VCAM-1/CD106 (1:50; LSBio, Seattle, WA). The sections were then stained with either rabbit anti-goat horseradish peroxidase (1:150; Dako, Glostrup, Denmark) or rabbit anti-mouse Envision horseradish peroxidase (Dako) secondary antibodies; diaminobenzidine (Dako) was used as the chromogen.

\section{Immunofluorescence}

Double-labeled immunofluorescence was performed on paraffin-embedded tissue sections ( $4 \mu \mathrm{m}$ thick). Antigen retrieval was performed, as described in Table 1, and the sections were costained with goat anti-human endoglin 
Table 1 Antibodies Used for Immunofluorescence Staining

\begin{tabular}{|c|c|c|c|c|c|c|}
\hline Tissue & Costaining & Antigen retrieval & Primary & Dilution/company & Secondary & Dilution/company \\
\hline \multirow[t]{10}{*}{ Human } & \multirow[t]{2}{*}{ Endoglin + CD31 } & \multirow[t]{2}{*}{ Tris/EDTA (pH 9) } & $\begin{array}{l}\text { Goat anti-human } \\
\text { endoglin }\end{array}$ & $\begin{array}{l}\text { 1:800/R\&D Systems } \\
\text { (Minneapolis, } \\
\text { MN) }\end{array}$ & $\begin{array}{c}\text { Donkey anti-goat } \\
\text { IgG Alexa } 546\end{array}$ & $\begin{array}{l}\text { 1:200/Thermo } \\
\text { Fisher Scientific } \\
\text { (Waltham, MA) }\end{array}$ \\
\hline & & & $\begin{array}{l}\text { Mouse anti-human } \\
\text { CD31 }\end{array}$ & $\begin{array}{c}\text { 1:200/Dako } \\
\text { (Glostrup, } \\
\text { Denmark) }\end{array}$ & $\begin{array}{c}\text { Donkey anti-mouse } \\
\text { IgG Alexa } 488\end{array}$ & $\begin{array}{l}\text { 1:200/Thermo } \\
\text { Fisher Scientific }\end{array}$ \\
\hline & \multirow[t]{2}{*}{ Endoglin + CD68 } & \multirow[t]{2}{*}{ Tris/EDTA ( $\mathrm{pH} 9)$} & $\begin{array}{l}\text { Goat anti-human } \\
\text { endoglin }\end{array}$ & 1:800/R\&D Systems & $\begin{array}{c}\text { Donkey anti-goat } \\
\text { IgG Alexa } 546\end{array}$ & $\begin{array}{l}\text { 1:200/Thermo } \\
\text { Fisher Scientific }\end{array}$ \\
\hline & & & $\begin{array}{l}\text { Mouse anti-human } \\
\text { CD68 }\end{array}$ & 1:2000/Dako & $\begin{array}{c}\text { Donkey anti-mouse } \\
\text { IgG Alexa } 488\end{array}$ & $\begin{array}{l}\text { 1:200/Thermo } \\
\text { Fisher Scientific }\end{array}$ \\
\hline & \multirow[t]{2}{*}{ Endoglin $+\alpha$-SMA } & \multirow[t]{2}{*}{ Tris/EDTA (pH 9) } & $\begin{array}{l}\text { Goat anti-human } \\
\text { endoglin }\end{array}$ & 1:800/R\&D Systems & $\begin{array}{c}\text { Donkey anti-goat } \\
\text { IgG Alexa } 546\end{array}$ & $\begin{array}{l}\text { 1:200/Thermo } \\
\text { Fisher Scientific }\end{array}$ \\
\hline & & & $\begin{array}{l}\text { Mouse anti-human } \\
\alpha \text {-SMA }\end{array}$ & 1:400/Dako & $\begin{array}{c}\text { Donkey anti-mouse } \\
\text { IgG Alexa } 488\end{array}$ & $\begin{array}{l}\text { 1:200/Thermo } \\
\text { Fisher Scientific }\end{array}$ \\
\hline & \multirow[t]{2}{*}{ Endoglin + nephrin } & \multirow[t]{2}{*}{ Citrate $(\mathrm{pH} 6)$} & $\begin{array}{l}\text { Goat anti-human } \\
\text { endoglin }\end{array}$ & 1:200/R\&D Systems & $\begin{array}{c}\text { Donkey anti-goat } \\
\text { IgG Alexa } 488\end{array}$ & $\begin{array}{l}\text { 1:200/Thermo } \\
\text { Fisher Scientific }\end{array}$ \\
\hline & & & $\begin{array}{l}\text { Rabbit anti-human } \\
\text { nephrin }\end{array}$ & $\begin{array}{l}\text { 1:1000/LSBio } \\
\quad(\text { Seattle, WA })\end{array}$ & $\begin{array}{c}\text { Donkey anti-rabbit } \\
\text { IgG Alexa } 546\end{array}$ & $\begin{array}{l}\text { 1:200/Thermo } \\
\text { Fisher Scientific }\end{array}$ \\
\hline & \multirow[t]{2}{*}{ Endoglin + VCAM-1 } & \multirow[t]{2}{*}{ Citrate $(\mathrm{pH} 6)$} & $\begin{array}{l}\text { Goat anti-human } \\
\text { endoglin }\end{array}$ & 1:200/R\&D Systems & $\begin{array}{c}\text { Donkey anti-goat } \\
\text { IgG Alexa } 546\end{array}$ & $\begin{array}{l}\text { 1:200/Thermo } \\
\text { Fisher Scientific }\end{array}$ \\
\hline & & & $\begin{array}{l}\text { Mouse anti-human } \\
\text { CD106 (VCAM-1) }\end{array}$ & 1:50/LSBio & $\begin{array}{c}\text { Donkey anti-mouse } \\
\text { IgG Alexa } 488\end{array}$ & $\begin{array}{l}\text { 1:200/Thermo } \\
\text { Fisher Scientific }\end{array}$ \\
\hline \multirow[t]{2}{*}{ Mouse } & \multirow[t]{2}{*}{ Endoglin + PECAM1 } & \multirow[t]{2}{*}{ Tris/EDTA (pH 9) } & $\begin{array}{l}\text { Goat anti-human } \\
\text { endoglin }\end{array}$ & 1:800/R\&D Systems & $\begin{array}{c}\text { Donkey anti-goat } \\
\text { IgG Alexa } 488\end{array}$ & $\begin{array}{l}\text { 1:200/Thermo } \\
\quad \text { Fisher Scientific }\end{array}$ \\
\hline & & & $\begin{array}{l}\text { Rabbit anti-mouse } \\
\text { PECAM1 }\end{array}$ & $\begin{array}{c}\text { 1:400/Santa Cruz } \\
\text { Biotechnology } \\
\text { (Dallas, TX) }\end{array}$ & $\begin{array}{l}\text { Donkey anti-rabbit } \\
\text { IgG Alexa } 546\end{array}$ & $\begin{array}{l}\text { 1:200/Thermo } \\
\text { Fisher Scientific }\end{array}$ \\
\hline
\end{tabular}

PECAM1, platelet endothelial cell adhesion molecule $1 ; \alpha$-SMA, $\alpha$-smooth muscle actin.

(1:800; R\&D Systems) together with mouse anti-human CD31 (1:200; Dako), mouse anti-human CD68 (1:2000; Dako), mouse anti-human $\alpha$-smooth muscle actin (1:400; Dako), or rabbit anti-mouse platelet endothelial cell adhesion molecule 1 (1:400; Santa Cruz Biotechnology, Dallas, TX). Additional sections were also costained with goat anti-human endoglin (1:200; R\&D Systems) together with mouse antihuman VCAM-1/CD106 (1:50; LSBio) or rabbit anti-human nephrin (1:1000; LSBio). The stained sections were then incubated with the appropriate secondary IgG Alexa antibody (Table 1) and mounted with ProLong Gold antifade reagent containing DAPI (Life Technologies, Carlsbad, CA).

\section{Digital Image Analysis}

Immunohistochemically stained sections were imaged using a Philips Ultra-Fast Scanner 1.6 RA (Amsterdam, the Netherlands). ImageJ version 1.8.0 (NIH, Bethesda, MD; http://imagej.nih.gov/ij) was used to measure the glomerular levels of endoglin (mouse and human) and the glomerular levels of VCAM-1 (human). Mouse kidney sections were imaged at $\times 400$ magnification, and the positive area per glomerulus was measured in 25 glomeruli per section and corrected for the total area of each glomerulus. Human kidney sections were imaged at $\times 200$ magnification, and the positive area per glomerulus was measured in 10 glomeruli per section (resection material) or in all nonglobal sclerotized glomeruli (biopsy material) and corrected for the total area of each glomerulus. The examined glomeruli were selected at random, and the same glomeruli were used to measure VCAM-1 and endoglin in the human samples.

\section{Cell Culture}

Immortalized human endothelial cells $(\mathrm{ECRFs})^{20}$ that were transduced with a lentiviral vector expressing either an shRNA against endoglin $\left(\mathrm{ECRF}^{+/-}\right)$or a nontargeting control shRNA $\left(\mathrm{ECRF}^{+/+}\right)$were generously provided by Dr. Luuk Hawinkels (Department of Gastroenterology, Leiden University Medical Center). Compared with $\mathrm{ECRF}^{+/+}$, endoglin mRNA and protein levels in $\mathrm{ECRF}^{+/-}$were reduced by approximately $30 \%$ and $40 \%$, respectively (Supplemental Figure $\mathrm{S} 1, \mathrm{~A}$ and C). ECRFs were cultured at $37^{\circ} \mathrm{C}$ in $5 \% \mathrm{CO}_{2}$ in Medium 199 (Gibco Laboratories, Gaithersburg, MD) supplemented with $10 \%$ fetal bovine serum (Sigma-Aldrich), $0.4 \%$ penicillin-streptomycin (Gibco Laboratories), $0.2 \%$ unfractionated heparin (LEO Pharma, Ballerup, Denmark), and $25-\mathrm{mg}$ bovine pituitary extract (Gibco Laboratories). THP- 1 cells (ATCC, Manassas, VA) were cultured at $37^{\circ} \mathrm{C}$ in $5 \% \mathrm{CO}_{2}$ in RPMI 1640 medium (Gibco Laboratories) supplemented with $10 \%$ fetal bovine serum (Sigma-Aldrich) and $1 \%$ penicillin-streptomycin (Gibco Laboratories). Human 
umbilical vascular endothelial cells were cultured in Endothelial Cell Growth Medium-2 media (Lonza, Basel, Switzerland) at $37^{\circ} \mathrm{C}$ in $5 \% \mathrm{CO}_{2}$.

\section{Endothelial Cell Activation Assay}

$\mathrm{ECRF}^{+/+}$and $\mathrm{ECRF}^{+/-}$that were confluent for 2 days were incubated with $20 \mathrm{ng} / \mathrm{mL}$ vascular endothelial growth factor$\mathrm{A}_{165}$ (VEGF-A; R\&D Systems) for 2, 4, 6, or 8 hours. ${ }^{3}$ As control for VEGF-A, cells were incubated with $0.1 \%(\mathrm{w} / \mathrm{v})$ bovine serum albumin. To quantify changes in gene expression, total RNA was extracted using TRIzol (Ambion, Foster City, CA), in accordance with the manufacturer's instructions, and transcribed into cDNA. Real-time quantitative PCR was performed using the IQTM SYBR Green Supermix (Bio-Rad, Hercules, CA) with a CFX real-time system (Bio-Rad). $\mathrm{C}_{\mathrm{q}}$ (cycle quantification) values were normalized to the housekeeping gene HPRT1. The following primers were used in this study: endoglin $(E N G), 5^{\prime}$-CACTAGCCAGGTCTCGAAGG-3' (forward) and 5'-CTGAGGACCAGAAGCACCTC-3' (reverse); Eng, $5^{\prime}$ CTTCCAAGGACAGCCAAGAG-3' (forward) and $5^{\prime}$ GTGGTTGCCATTCAAGTGTG-3' (reverse); Eng (short isoform), $5^{\prime}$-TAGCACCTTGTCCCAGGAAG-3' (forward) and $5^{\prime}$-GTGGAGGCTTGGGATACTCA-3' (reverse); Eng (long isoform), $5^{\prime}$-TAGCACCTTGTCCCAGGAAG-3' (forward) and 5'-GGCCACGTGTGTGAGAATAG-3' (reverse); HPRT$1,5^{\prime}$-AGATGGTCAAGGTCGCAAGC-3' (forward) and $5^{\prime}$ TCAAGGGCATATCCTACAACAAAC- $3^{\prime}$ (reverse); ICAM1, $5^{\prime}$-CAGAGGTTGAACCCCACAGT-3' (forward) and $5^{\prime}$ CCTCTGGCTTCGTCAGAATC-3' (reverse); E-selectin (SELE), $5^{\prime}$-AGCCCAGAGCCTTCAGTGTA-3' (forward) and 5'-AACTGGGATTTGCTGTGTCC-3' (reverse); VCAM1 (Sino Biological, Beijing, China); plasminogen activator inhibitor-1 (PAI-1), 5'-ACTGGAAAGGCAACATGACC-3' (forward) and $5^{\prime}$-TGACAGCTGTGGATGAGGAG-3' (reverse); and connective tissue growth factor $(C T G F), 5^{\prime}$ CCTGGTCCAGACCACAGAGT-3' (forward) and 5'-TTGAGATTTTGGGAGTACGG-3' (reverse). These experiments were performed in triplicate.

\section{Immunoblotting}

$\mathrm{ECRF}^{+/+}$and $\mathrm{ECRF}^{+/-}$that were confluent for 2 days were serum starved for 5 hours. Cells were then incubated with 20 $\mathrm{ng} / \mathrm{mL}$ VEGF-A (R\&D Systems) for 5, 10, 15, 30, and 60 minutes. Cells were washed with ice-cold phosphate-buffered saline and lysed in buffer containing 1\% (w/v) SDS, trisbuffered saline, $10 \mathrm{mmol} / \mathrm{L}$ EDTA, and protease and phosphatase inhibitor cocktails (Roche, Basel, Switzerland). Protein concentration was determined by using a detergentcompatible protein assay (Bio-Rad). A twofold serial dilution of a human umbilical vascular endothelial cell lysate (from 20 to $0.16 \mu \mathrm{g}$ ) was used to generate a calibration curve to calculate relative endoglin protein levels in unstimulated and VEGF-A-stimulated ECRF ${ }^{+/-}$and $\mathrm{ECRF}^{+/+}$. Protein lysates were subjected to SDS-PAGE and subsequent Western blot analysis. Membranes were blocked for 1 hour in 5\% bovine serum albumin/tris-buffered saline with Tween 20 and then incubated overnight with primary antibodies against phosphorylated Akt (Ser473), Akt, phosphorylated ERK1/2 (Thr202/Tyr204), ERK1/2, phosphorylated ATF-2 (Thr71), and ATF-2 (all from Cell Signaling Technology, Danvers, MA); glyceraldehyde-3-phosphate dehydrogenase (Cell Signaling Technology) was used as a loading control. Secondary antibodies were horseradish peroxidase conjugated. Signals were visualized by chemiluminescent detection, according to the manufacturer's protocol (SuperSignal West Pico; Thermo Fisher Scientific, Waltham, MA). Band intensity was quantified using Image Lab 6.0.1 software (Bio$\mathrm{Rad})$. These experiments were performed in triplicate. Membranes were also incubated in goat anti-human endoglin (R\&D Systems) as the primary antibody, followed by an IRDye Infrared Fluorescent (LI-COR Biosciences, Lincoln, NE) secondary antibody. Signals were visualized using the LICOR Odyssey Infrared Imaging System (LI-COR Biosciences). Band intensity was quantified using Odyssey V3.0 software (LI-COR Biosciences). Human umbilical vascular endothelial cell protein concentrations and band intensities were used to calculate a calibration curve for measuring endoglin protein levels; this calibration curve was then used to quantify endoglin protein levels in $\mathrm{ECRF}^{+/+}$and $\mathrm{ECRF}^{+/-}$.

To inhibit Akt phosphorylation, $\mathrm{ECRF}^{+/+}$and $\mathrm{ECRF}^{+/-}$ that were confluent for 2 days were incubated for 1 hour with wortmannin (3 nmol/L; Selleckchem, Houston, TX), followed by 15 minutes of stimulation with $20 \mathrm{ng} / \mathrm{mL}$ VEGFA (R\&D Systems). Cells were lysed, as described above, and subjected to SDS-PAGE and subsequent Western blot analysis. Primary antibodies were directed against phosphorylated Akt (Ser473), Akt, phosphorylated ATF-2 (Thr71), and ATF-2 (all from Cell Signaling Technology); glyceraldehyde-3-phosphate dehydrogenase was used as a loading control. IRDye Infrared Fluorescent antibodies were used as the secondary antibody, and the signals were visualized using the LI-COR Odyssey Infrared Imaging System. Band intensity was quantified using Odyssey V3.0 software. The ratio of phosphorylated/nonphosphorylated proteins was used to calculate whether the differences between $\mathrm{ECRF}^{+/+}$ and $\mathrm{ECRF}^{+/-}$were significant.

\section{Monocyte Adhesion Assay}

$\mathrm{ECRF}^{+/+}$and $\mathrm{ECRF}^{+/-}$were plated in 96-well plates and grown to confluence. Cells were then stimulated with $20 \mathrm{ng} / \mathrm{mL}$ VEGF-A (or $0.1 \%$ bovine serum albumin) for $2,4,6$, or 24 hours, after which 150,000 Hoechst-labeled THP-1 cells were added to each well. Cells were incubated for 30 minutes at $37^{\circ} \mathrm{C}$ under static conditions. Subsequently, ECRFs were washed with phosphate-buffered saline to remove the unbound THP-1 cells. Cells were then fixed in $100 \mu \mathrm{L} 4 \%$ paraformaldehyde in phosphate-buffered saline (Merck Millipore, Billerica, MA) for 10 minutes, followed by two washes with phosphate-buffered saline. The number of attached THP-1 cells was measured 
with an ArrayScan XTI High Content Platform (Thermo Fisher Scientific) using a $5 \times$ objective; nine fields of view were measured. These experiments were performed in triplicate.

\section{Statistical Analysis}

Data of the independent experimental repeats are expressed as the means $\pm \mathrm{SD}$. Differences between groups were analyzed using the two-tailed unpaired $t$-test or one-way analysis of variance, where appropriate. To analyze the relationship between VCAM-1 and endoglin levels, a linear regression was performed. To this end, the glomerular endoglin and glomerular VCAM-1 - positive areas in patients with diabetic nephropathy were log transformed to obtain a linear relationship. A linear mixed model was used to account for the correlation of repeated measurements within patients. Differences were considered significant at $P<0.05$.

\section{Results}

\section{Diabetic Mice Have Increased Glomerular Endoglin Expression}

First, the expression of endoglin was measured in the glomeruli of mice 5 and 15 weeks after the induction of diabetes. At both time points, diabetic mice had significantly higher levels of endoglin compared with age-matched nondiabetic mice $(P<0.001)$ (Figure $1, \mathrm{~A}-\mathrm{C})$. Further analysis revealed that endoglin is expressed primarily in endothelial cells (Figure 1, D-F). Two isoforms of endoglin exist, the long and short isoforms, which have been described to have opposite effects on angiogenesis. ${ }^{21}$ Therefore, a shift in the expression of these isoforms might be involved in the development of endothelial cell activation and subsequent renal disease. No significant difference in either the short or the long endoglin isoform was found between diabetic mice and agematched nondiabetic controls $(P=0.11$ and $P=0.35$, respectively); no significant difference was found in total endoglin mRNA levels either $(P=0.78)$ (Supplemental
Figure S2). This suggests that the increased endoglin protein levels in diabetic mice were likely caused by changes at the translational and/or posttranslational level, and not by an increase in endoglin transcription or mRNA stability.

\section{Endoglin Is Expressed in Human Glomerular Endothelial Cells}

Endoglin expression was then analyzed in the glomeruli of human kidneys obtained from nondiabetic controls and from patients with diabetic nephropathy. Coimmunostaining for endoglin and the endothelial marker CD31 showed that endoglin is expressed in glomerular endothelial cells (Figure 2). Interestingly, the colocalization of endoglin and CD31 was less robust in patients with diabetic nephropathy compared with nondiabetic controls; this difference is likely because of reduced CD31 expression in glomerular endothelial cells in the patients with diabetic nephropathy. ${ }^{22}$ Coimmunostaining for endoglin and $\alpha$-smooth muscle actin-which can be expressed in mesangial cells in a variety of kidney diseases, including diabetic nephropathy ${ }^{23-27}$ - suggests that mesangial cells may also express endoglin (Supplemental Figure S3, A-C). Furthermore, coimmunostaining for endoglin, together with either nephrin or CD68, revealed that endoglin is not expressed in either podocytes or glomerular macrophages (Supplemental Figure S3, D-I).

In contrast to our findings in diabetic mice, glomerular endoglin levels were similar between patients with diabetic nephropathy and nondiabetic controls $(P=0.874)$ (Figure 3A). However, the level of endoglin expression varied widely between glomeruli within some patients, as shown in Figure 3, B and C. This suggests that activation of glomerular endothelial cells also varies within patients.

\section{VCAM-1 Expression Is Increased in Glomerular Capillaries of Patients with Diabetic Nephropathy}

Next, it was investigated whether endothelial cell activation is increased in patients with diabetic nephropathy, and it was
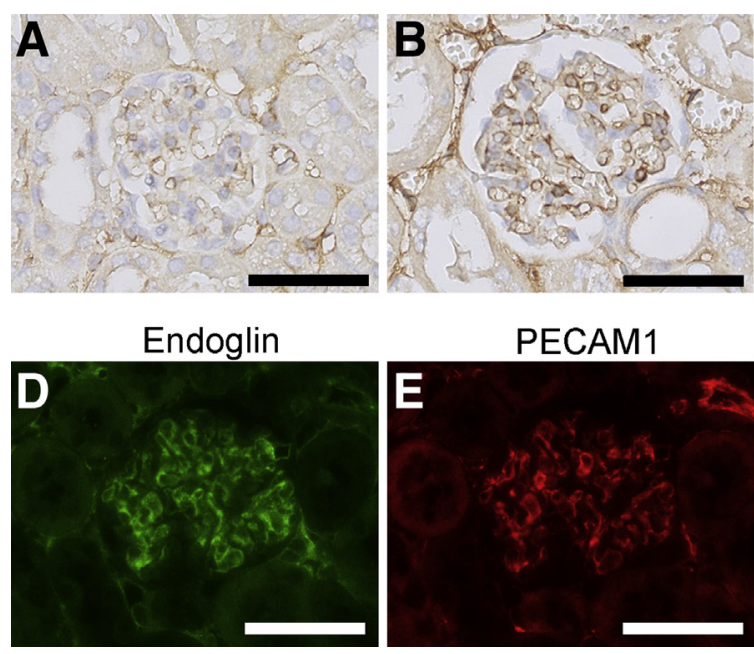

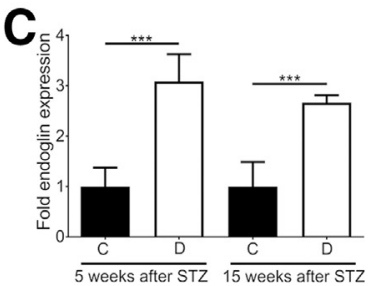

Merge

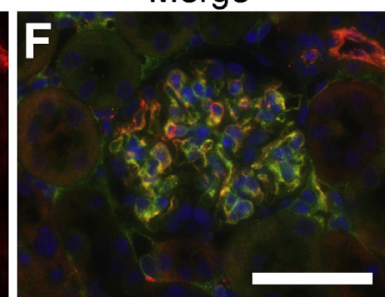

Figure 1 Glomerular endoglin expression is up-regulated in mice with experimentally induced diabetic nephropathy. A and B: Representative images of endoglin immunostaining in the glomeruli of an age-matched, nondiabetic control mouse (A) and a diabetic mouse 5 weeks after streptozotocin-induced diabetes (B). C: Quantitative analysis of endoglin protein levels in the glomeruli of diabetic mice 5 and 15 weeks after streptozotocin-induced diabetes (D), relative to the protein levels measured in age-matched nondiabetic mice (C). D and E: Representative images of endoglin (green; D) and platelet endothelial cell adhesion molecule 1 (PECAM-1; red; E) immunofluorescence in a kidney section obtained from a diabetic mouse. F: The merged image. The nuclei were counterstained with DAPI (blue). ${ }^{* *} P<0.001$ ( $t$-test). Scale bars $=50 \mu \mathrm{m}(\mathbf{A}, \mathbf{B}$, and $\mathbf{D}-\mathbf{F})$. 

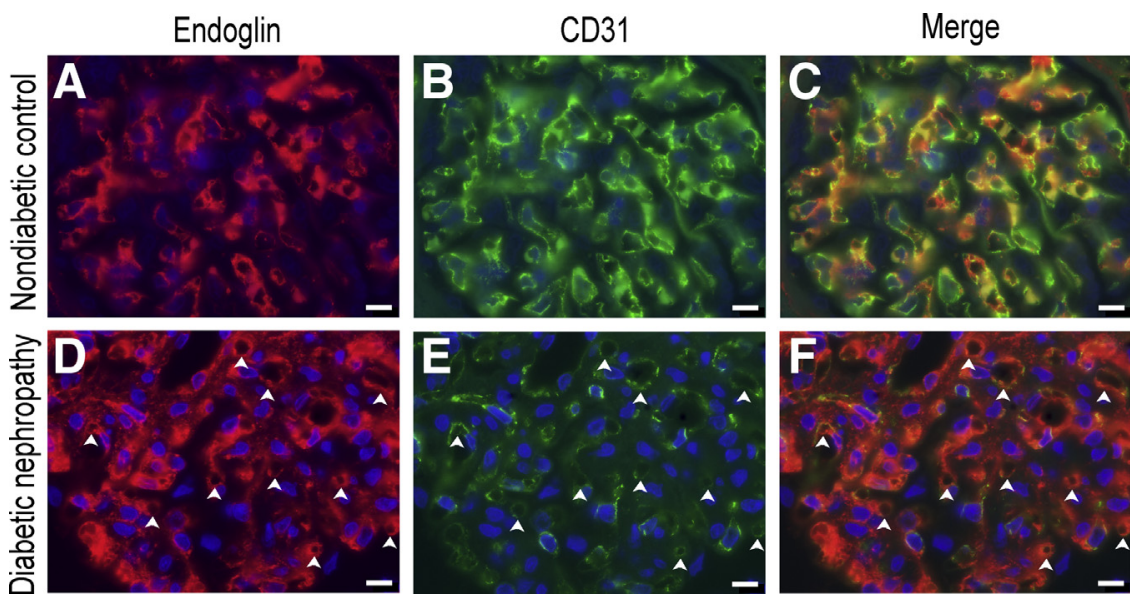

Figure 2 Endoglin is expressed in glomerular endothelial cells in patients with diabetic nephropathy. Representative images of endoglin (red; $\mathbf{A}$ and D) and CD31 (green; $\mathbf{B}$ and E) immunofluorescence in kidney sections obtained from a nondiabetic control $(\mathbf{A}-\mathbf{C})$ and a patient with diabetic nephropathy $(\mathbf{D}-\mathbf{F})$. E: Note the reduced CD31 immunostaining in the patient with diabetic nephropathy. D-F: The arrowheads indicate examples of colocalization between endoglin and CD31. The nuclei were counterstained with DAPI (blue). Scale bars $=10 \mu \mathrm{m}(\mathbf{A}-\mathbf{F})$.

examined whether high glomerular endoglin expression is correlated with endothelial cell activation. Kidney sections were, therefore, coimmunostained for endoglin and the endothelial cell activation marker VCAM-1 (Figure 3, G-I). VCAM-1 colocalized with endoglin in the glomeruli of patients with diabetic nephropathy. In addition, immunohistochemistry showed that the relative glomerular VCAM-1-positive area was significantly higher in patients with diabetic nephropathy compared with nondiabetic controls $(P<0.001)$ (Figure 3D). Similar to endoglin-stained sections, glomerular VCAM-1 levels were highly variable within patients (Figure 3, E and F). More important, when the glomerular VCAM-1-positive
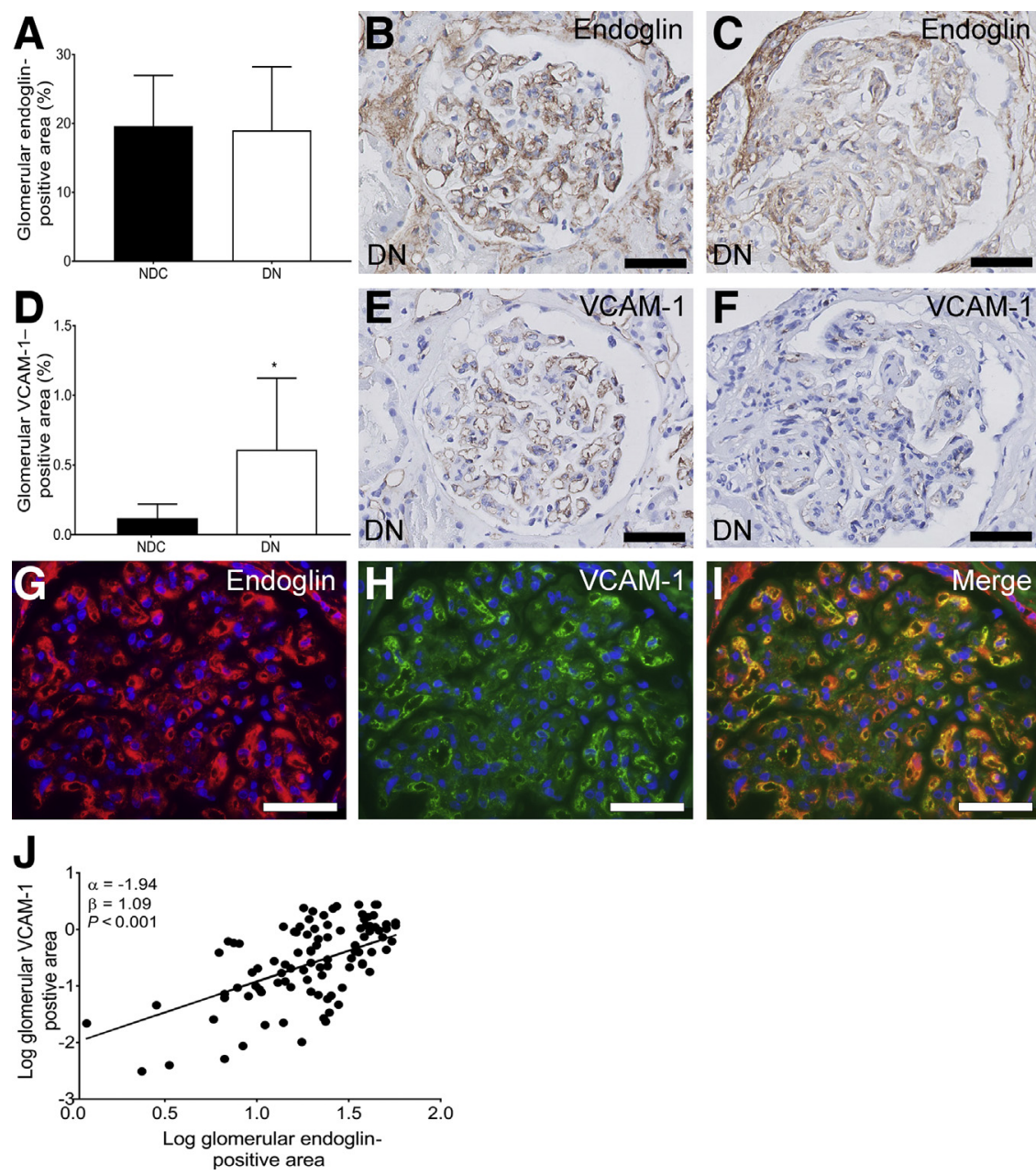

Figure 3 Glomerular endoglin protein levels are correlated with endothelial cell activation in patients with diabetic nephropathy. A-F: Endoglin $(\mathbf{A}-\mathbf{F})$ and VCAM-1 (A-C) immunohistochemistry and quantification (D-F). A and $\mathbf{D}$ : Endoglin-positive glomerular area (A) and VCAM1-positive glomerular area (D) were measured in patients with diabetic nephropathy (DN; white bars) and nondiabetic controls (NDCs; black bars). B, C, E, and F: The images show glomerular endoglin ( $\mathbf{B}$ and $\mathbf{C}$ ) and glomerular VCAM-1 (E and F) immunohistochemistry in adjacent sections from a single patient with diabetic nephropathy; note the high variability in both endoglin and VCAM-1 staining. B, C, E, and F: Also note that the glomerulus with high endoglin staining (B) has high VCAM-1 staining (E), and the glomerulus with low endoglin staining (C) has low VCAM-1 staining (F). G-I: Example images of endoglin (red; G) and VCAM-1 (green; H) immunofluorescence in a kidney section obtained from a patient with diabetic nephropathy showing colocalization (I). The nuclei were counterstained with DAPI (blue). J: Linear mixed-model regression analysis of the correlation between log-transformed endoglin-positive area (on the $x$ axis) and VCAM-1-positive area (on the $y$ axis) in the glomeruli of patients with diabetic nephropathy. Each symbol represents an individual glomerulus, and the solid line shows the linear regression. The difference in -2 log likelihood $(\beta=1.09)$ between the models is highly significant $(P<0.001)$, indicating that glomerular endoglin levels are significantly correlated with glomerular VCAM-1 levels. ${ }^{*} P<0.05$ versus NDC (t-test). Scale bars $=50 \mu \mathrm{m}(\mathbf{B}, \mathbf{C}, \mathbf{E}, \mathbf{F}$, and $\mathbf{G}-\mathbf{I})$. 
area was plotted against the glomerular endoglin-positive area, the difference in $-2 \log$ likelihood $(\beta=1.09)$ between the models was highly significant $(P<0.001)$. This indicates that glomerular endoglin levels are significantly correlated with glomerular VCAM-1 levels in patients with diabetic nephropathy (Figure 3J), meaning that glomeruli with increased levels of endoglin also have increased levels of VCAM-1.

\section{Endoglin Mediates the Activation of Endothelial Cells}

Because endoglin expression was up-regulated in the glomerular endothelial cells of diabetic mice, and glomerular endoglin levels correlated with glomerular VCAM-1 levels in patients with diabetic nephropathy, we hypothesized that endoglin might play a role in mediating the activation of these cells, as well as subsequent glomerular inflammation. In turn, lowering endoglin expression may prevent endothelial cell activation and monocyte binding to endothelial cells. To test this hypothesis, two immortalized human endothelial cell lines that express either normal $\left(\mathrm{ECRF}^{+/+}\right)$or $30 \%$ reduced $\left(\mathrm{ECRF}^{+/-}\right)$levels of endoglin were used (Supplemental Figure S1). These cells were stimulated with $20 \mathrm{ng} / \mathrm{mL}$ VEGF-A for 2 to 8 hours, after which the mRNA levels of VCAM1, SELE, and ICAMI (which encode vascular cell adhesion molecule 1, E-selectin, and intercellular adhesion molecule 1 , respectively) were measured using real-time quantitative PCR. VEGF-A induced the rapid and robust activation of $\mathrm{ECRF}^{+/+}$, as illustrated by increased expression of both VCAM1 and SELE (Figure 4). In contrast, VEGF-A had little effect on $V C A M 1$ or SELE expression in $\mathrm{ECRF}^{+/-}$, indicating that these cells have impaired VEGF-A-induced activation.
ICAMI expression was not affected by VEGF-A stimulation in either $\mathrm{ECRF}^{+/+}$or $\mathrm{ECRF}^{+/}$(Figure 4). To investigate whether endoglin affects endothelial cell activation by modifying transforming growth factor (TGF)- $\beta$ signaling, the mRNA levels of PAI- 1 and $C T G F$, which are downstream target genes of TGF- $\beta$ signaling, ${ }^{28,29}$ were measured. Stimulating either $\mathrm{ECRF}^{+/+}$or $\mathrm{ECRF}^{+/-}$with VEGF-A had no effect on the mRNA levels of PAI-1 or CTGF (Figure 4). This finding suggests that endoglin modifies VEGFA-induced endothelial cell activation via a mechanism independent of canonical TGF- $\beta$ signaling.

\section{Reduced Endoglin Levels Diminish Endothelial Cell Activation by Increasing Akt Phosphorylation}

Because reduced endoglin expression resulted in diminished endothelial cell activation on VEGF-A stimulation, it was also investigated whether VEGF-A stimulation affects endoglin protein levels. VEGF-A stimulation reduced endoglin protein levels in $\mathrm{ECRF}^{+/+}$; in contrast, endoglin protein levels were unaffected by VEGF-A stimulation in ECRF ${ }^{+-}$(Supplemental Figure S1, B and C). Next, it was investigated whether changes in endoglin expression altered VEGFR2 downstream signaling. Stimulation of $\mathrm{ECRF}^{+/+}$with VEGF-A led to a rapid increase in ERK1/2 phosphorylation (Figure 5 and Supplemental Figure S4). Basal Akt phosphorylation was strong in unstimulated $\mathrm{ECRF}^{+/+}$, which might be attributable to serum starvation. ${ }^{30}$ Akt phosphorylation initially decreased after VEGF-A stimulation, but then increased over time and peaked at 15 to 30 minutes. In addition, VEGF-A induced ATF-2 phosphorylation, thereby confirming other studies in endothelial cells. ${ }^{8}$ In $\mathrm{ECRF}^{+/-}$, VEGF-A induced ERK1/2
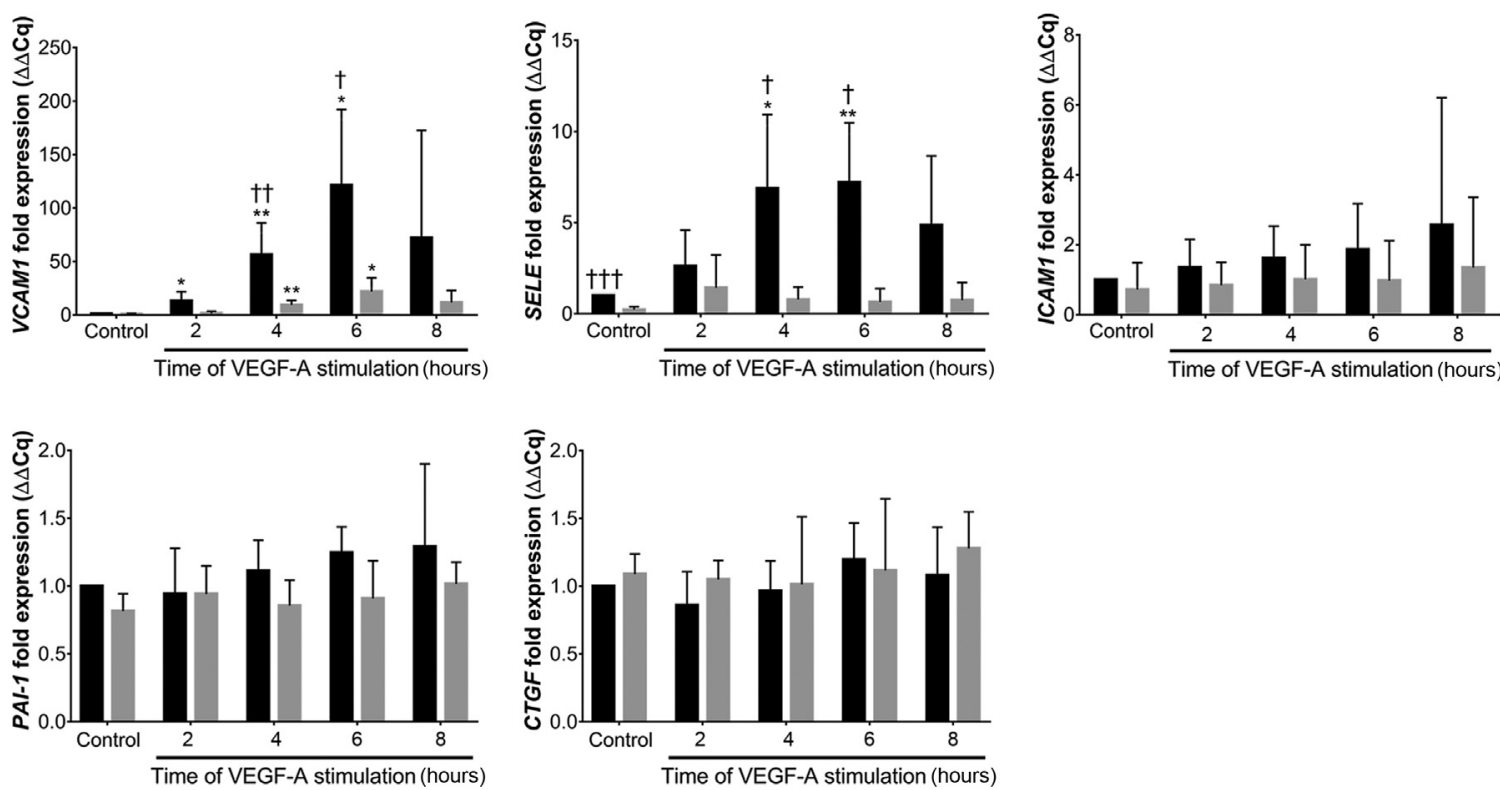

Figure 4 Endoglin mediates vascular endothelial growth factor (VEGF)-A-induced endothelial cell activation independent of transforming growth factor- $\beta$ signaling. VCAM1, SELE, ICAM1, PAI-1, and CTGF mRNA levels were measured in $\mathrm{ECRF}^{+/+}$(black bars) and $\mathrm{ECRF}^{+/-}$(gray bars). Where indicated, the cells were incubated for the indicated times with $20 \mathrm{ng} / \mathrm{mL}$ VEGF-A. Expression levels are displayed relative to the respective unstimulated ECRF (control). ${ }^{*} P<0.05,{ }^{* *} P<0.01$ versus the respective unstimulated control; ${ }^{\dagger} P<0.05,{ }^{\dagger \dagger} P<0.01$, and ${ }^{\dagger \dagger} P<0.001$ versus $\mathrm{ECRF}^{+/-}$at the same time point. Cq, cycle quantification. 

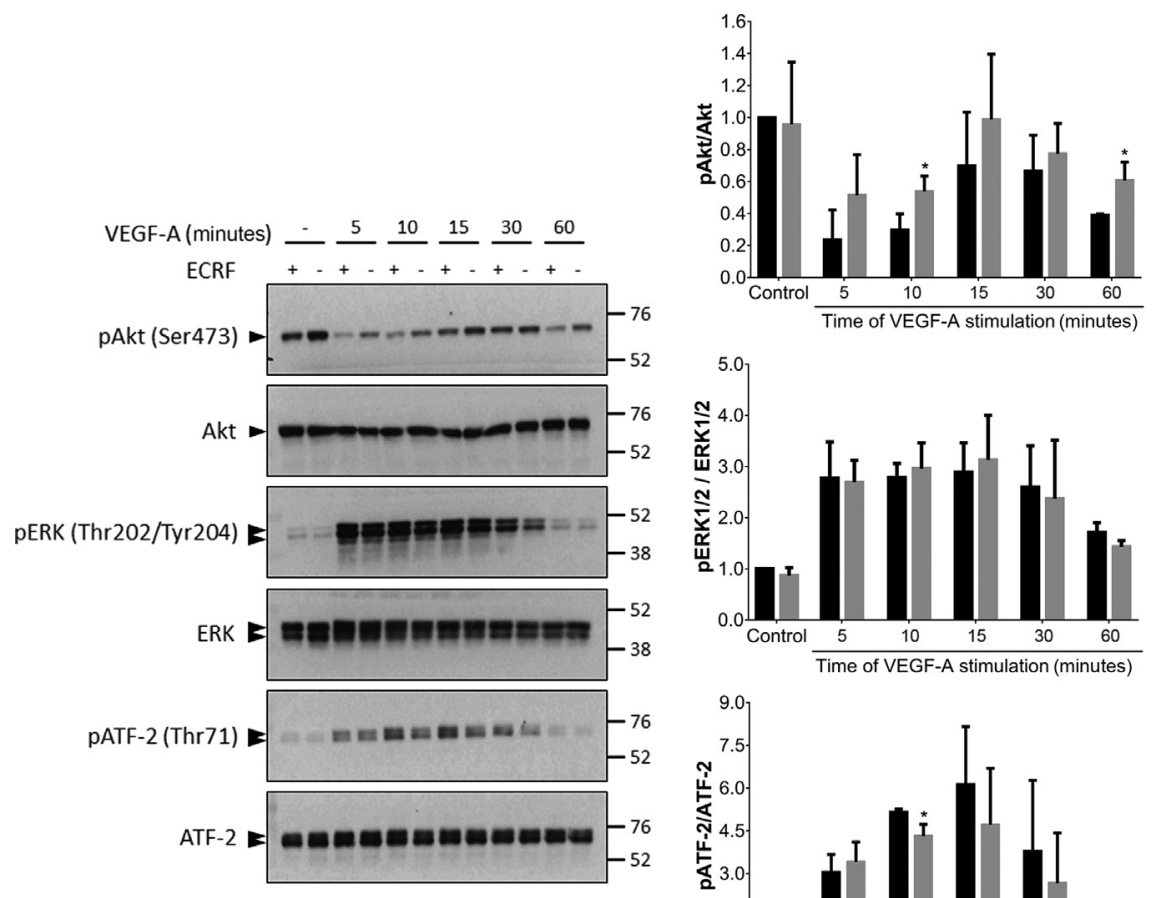

Figure 5 Akt phosphorylation is increased in endothelial cells with reduced endoglin expression. $\mathrm{ECRF}^{+/+}(+;$black bars $)$and $\mathrm{ECRF}^{+/-}(-$; gray bars) were incubated with vascular endothelial growth factor (VEGF)-A (20 ng/mL) for the

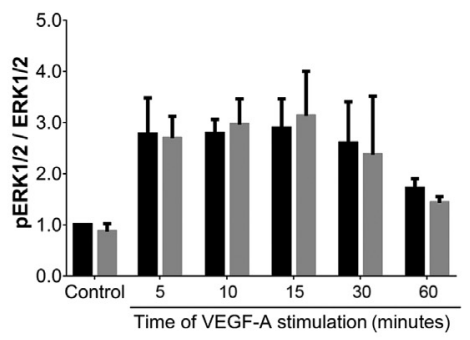
indicated times. VEGF-A-induced Akt phosphorylation is higher in $\mathrm{ECRF}^{+/-}$compared with $\mathrm{ECRF}^{+/+}$, whereas ATF-2 phosphorylation is lower in $\mathrm{ECRF}^{+/-}$. The VEGF-A-mediated effects are significantly different between the two cell lines after 10 minutes of stimulation. VEGF-A also increases extracellular signal-regulated kinases 1 and 2 (ERK1/2) phosphorylation; however; this increase is similar between $\mathrm{ECRF}^{+/+}$and $\mathrm{ECRF}^{+/-}$. The summary data are presented as the means \pm SD of three independent experiments. ${ }^{*} P<0.05$ versus $\mathrm{ECRF}^{+/+}$at the same time point. ATF-2, activating transcription factor 2 .

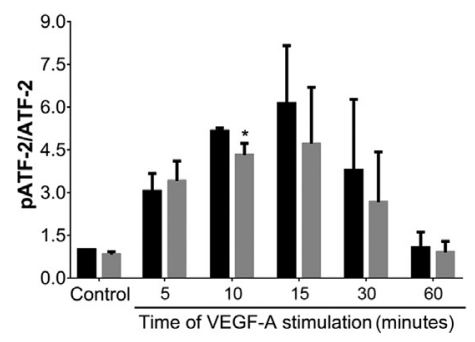

phosphorylation to a similar degree as in $\mathrm{ECRF}^{+/+}$(Figure 5 and Supplemental Figure S4). Yet, phosphorylation of Akt was stronger in $\mathrm{ECRF}^{+/-}$than in $\mathrm{ECRF}^{+/+}$, both after VEGF stimulation and under basal conditions. In contrast to $\mathrm{ECRF}^{+/+}$, phosphorylation of ATF-2 was significantly reduced in $\mathrm{ECRF}^{+/-}$on stimulation with VEGF-A. Wortmannin inhibited Akt phosphorylation in both $\mathrm{ECRF}^{+/+}$and $\mathrm{ECRF}^{+/-}$and increased the phosphorylated ATF-2/ATF-2 ratio on VEGF-A stimulation (Figure 6 and Supplemental Figure S5). Taken together, these results suggest that endoglin affects VEGFA-mediated activation of endothelial cells by reducing Akt phosphorylation and thereby promoting ATF-2-induced transcription of VCAM1.

\section{Endoglin Mediates the Adhesion of Monocytes to Activated Endothelial Cells}

Next, the consequences of impaired endothelial cell activation were investigated via reduced endoglin expression by measuring the adhesion of monocytes to endothelial cells. Both $\mathrm{ECRF}^{+/+}$and $\mathrm{ECRF}^{+/-}$were stimulated with $20 \mathrm{ng} /$ mL VEGF-A for 2, 4, 6, or 24 hours, after which THP-1 cells (a human leukemia monocytic cell line) were applied for 30 minutes. The number of THP-1 cells that adhered to the $\mathrm{ECRF}^{+/+}$and $\mathrm{ECRF}^{+/-}$were then counted.

In $\mathrm{ECRF}^{+/+}$, VEGF-A significantly increased the adhesion of monocytes; in contrast, VEGF-A stimulation had no effect on the adhesion of monocytes to $\mathrm{ECRF}^{+/-}$(Figure 7). These results indicate that endoglin expression plays a role in the adhesion of monocytes to endothelial cells activated by VEGF-A.

\section{Discussion}

Herein, it was shown that the expression of glomerular endoglin is increased in a mouse model of type 1 diabetes and that endoglin plays an important role in VEGFA-induced endothelial cell activation and in monocyte adhesion to VEGF-A-activated endothelial cells by regulating VEGFR2 signaling. Furthermore, it was shown that glomerular endoglin expression is positively correlated with glomerular VCAM-1 levels in patients with diabetic nephropathy, providing clinical evidence that endoglin mediates endothelial cell activation in diabetic nephropathy.

Endothelial cell activation is characterized by the increased surface expression of adhesion molecules, such as VCAM-1, ICAM-1, and E-selectin ${ }^{6}$; increased endothelial permeability; and a prothrombotic and proinflammatory phenotype. ${ }^{7}$ In the context of diabetes, a variety of factors can activate endothelial cells, including hyperglycemia, ${ }^{31}$ advanced glycation end products, ${ }^{32}$ oxidative stress, ${ }^{33}$ hyperlipidemia, ${ }^{34}$ hyperinsulinemia, ${ }^{35}$ proinflammatory cytokines, ${ }^{36}$ and growth factors, such as VEGF-A. ${ }^{3}$ The increase in adhesion molecules on endothelial cells facilitates the binding and infiltration of monocytes, ${ }^{9}$ which then produce cytokines that induce the typical glomerular changes associated with diabetic nephropathy, including mesangial matrix expansion. ${ }^{37}$ 


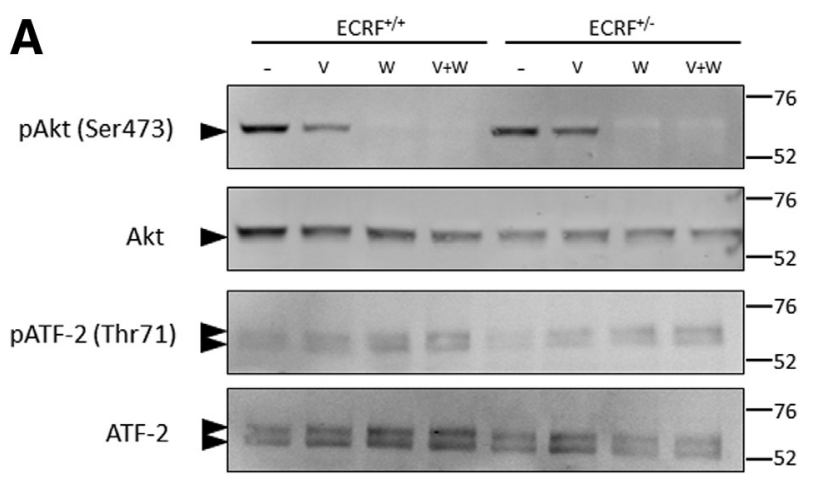

B

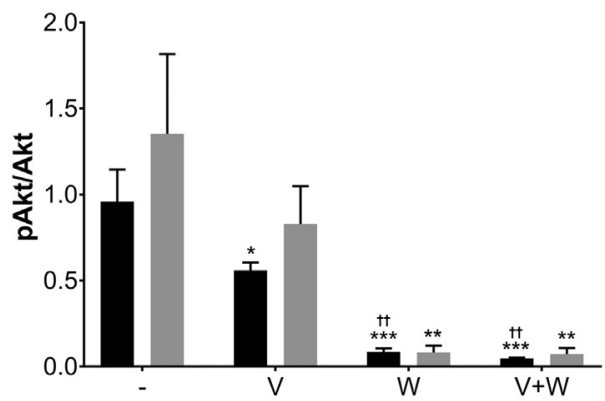

C

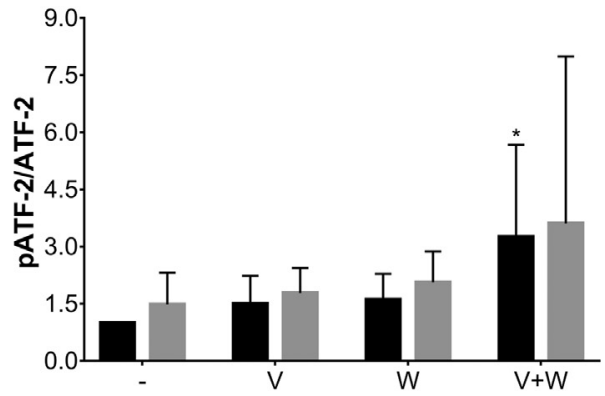

Figure 6 Inhibiting Akt phosphorylation increases vascular endothelial growth factor (VEGF)-A-induced phosphorylation of activating transcription factor 2 (ATF-2). $\mathrm{ECRF}^{+/+}$and $\mathrm{ECRF}^{+/-}$were incubated with wortmannin (W; $3 \mathrm{nmol} / \mathrm{L}$ ) for 1 hour, then stimulated with VEGF-A (V; $20 \mathrm{ng} / \mathrm{mL})$ for 15 minutes. A: Representative Western blot analysis. B and C: Quantification of the Western blot data shows that wortmannin reduces VEGF-A-mediated Akt phosphorylation (B) and increases ATF-2 phosphorylation (C). The summary data are presented as the means \pm SD of four experiments and are plotted relative to unstimulated $\mathrm{ECRF}^{+/+}(\mathbf{B}$ and $\mathbf{C})$. ${ }^{*} P<0.05,{ }^{*} P<0.01$, and $* * * P<0.001$ versus the respective unstimulated control; ${ }^{\dagger \dagger} P<0.01$ versus VEGF-A-stimulated $\mathrm{ECRF}^{+/+}$(one-way analysis of variance).

Using animal models of diabetic nephropathy, it has been shown that the expression of both VCAM- 1 and ICAM- 1 is increased in glomerular capillaries, ${ }^{17,38,39}$ suggesting that endothelial cell activation may play a role in the pathogenesis of diabetic nephropathy. Accordingly, deleting ICAM-1 expression in diabetic mice leads to decreased glomerular and interstitial macrophages, reduced albuminuria, and reduced renal fibrosis. ${ }^{40,41}$ Herein, we report that the TGF- $\beta$ coreceptor endoglin may play a role in endothelial activation in diabetic nephropathy.

Several studies using animal models showed that endoglin is up-regulated after renal injury and contributes to the severity of renal damage, ${ }^{42-44}$ possibly by boosting endothelial cell activation and the subsequent infiltration of macrophages. ${ }^{43}$ In our study, we found that glomerular endothelial endoglin levels were increased in an animal model of type 1 diabetes both 5 and 15 weeks after diabetes was induced. Using an in vitro system, it was found that stimulation with VEGF-A caused endothelial cell activation, as evidenced by increased levels of VCAM1 and SELE expression. However, in contrast with other studies, ${ }^{3,45}$ no change was found in the expression of ICAM1. This apparent discrepancy may be, at least in part, because mRNA levels, rather than protein levels, were measured. Interestingly, the activation of endothelial cells with downregulated endoglin expression $\left(\mathrm{ECRF}^{+-}\right)$was reduced after stimulation with VEGF-A, with virtually no up-regulation in VCAMI or SELE expression. This finding may be because of endoglin's effect on the kinetics and downstream signaling of the VEGFR2. ${ }^{15}$ Because expression of the TGF- $\beta$ target genes PAI- 1 and $C T G F$ was unaffected by VEGF-A stimulation in both $\mathrm{ECRF}^{+/+}$and $\mathrm{ECRF}^{+/-}$, it is unlikely that the canonical TGF- $\beta$ signaling pathway plays a significant role in the endoglin-dependent effects of VEGFA on endothelial cells. However, because the downstream targets overlap partially between VEGF-A and noncanonical TGF- $\beta$ signaling, the possibility that the TGF- $\beta$ noncanonical pathway plays a minor role cannot be ruled out.

Analysis of VEGFR2 downstream signaling demonstrated that, in contrast to $\mathrm{ECRF}^{+/+}, \mathrm{ECRF}^{+/-}$had a stronger phosphorylation of Akt, as reported earlier. ${ }^{15}$ Furthermore, $\mathrm{ECRF}^{+/-}$had a reduced phosphorylation of ATF-2 compared with $\mathrm{ECRF}^{+/+}$. ATF-2 is essential for VEGF-A-induced endothelial cell activation, ${ }^{8}$ and ATF-2 phosphorylation is decreased by the Akt pathway. ${ }^{16}$ Therefore, endothelial cell activation may be diminished in $\mathrm{ECRF}^{+-}$by increased Akt phosphorylation, which, in turn, down-regulates the activation of ATF-2. This notion is supported by the finding that inhibiting Akt phosphorylation results in an increase in the

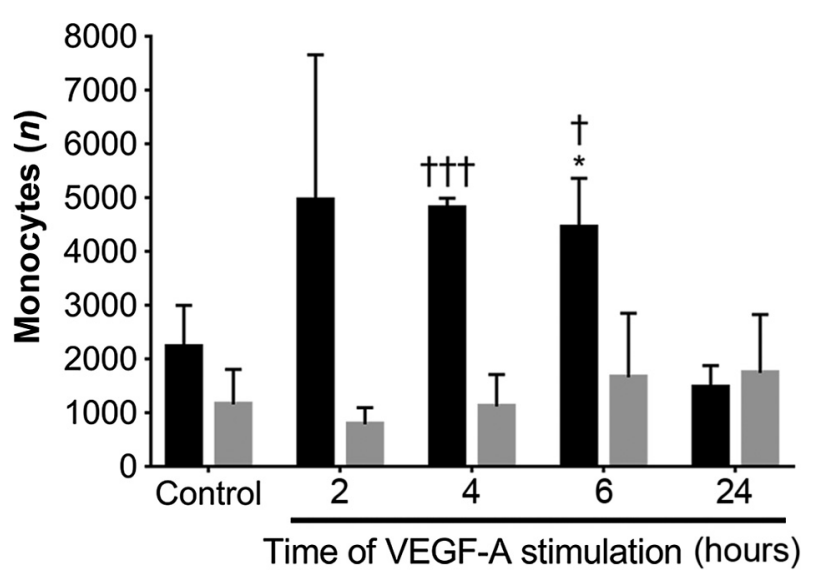

Figure 7 Endoglin mediates the adhesion of monocytes to activated endothelial cells. $\mathrm{ECRF}^{+/+}$(black bars) and $\mathrm{ECRF}^{+/-}$(gray bars) were incubated with vascular endothelial growth factor (VEGF)-A $(20 \mathrm{ng} / \mathrm{mL})$ for the indicated times, and the number of adherent Hoechst-stained THP-1 cells was counted. ${ }^{*} P<0.05$ versus the respective unstimulated control group; ${ }^{\dagger} P<0.05,{ }^{\dagger \dagger} P<0.001$ versus the respective $\mathrm{ECRF}^{+/-}$group at the same time point ( $t$-test). 
pATF-2/ATF-2 ratio on stimulation with VEGF-A. Figure 8 schematically illustrates our hypothesis on VEGFA-induced endothelial cell activation in cells with different endoglin levels. Briefly, on VEGF-A stimulation of endoglinproficient endothelial cells, endoglin colocalizes with VEGFR2 in early endosomes ${ }^{15}$ and is associated with ERK1/ 2 phosphorylation. ${ }^{8}$ In contrast, when endoglin expression is reduced, phosphorylation of Akt is increased, thereby reducing ATF-2 phosphorylation and subsequent VCAM1 expression. ${ }^{15,16}$ The Akt pathway can be activated by plasma membrane-bound VEGFR2, whereas the ERK1/2pathway cannot, ${ }^{46}$ suggesting that endoglin regulates the internalization and intracellular signaling processes of the VEGFR2.

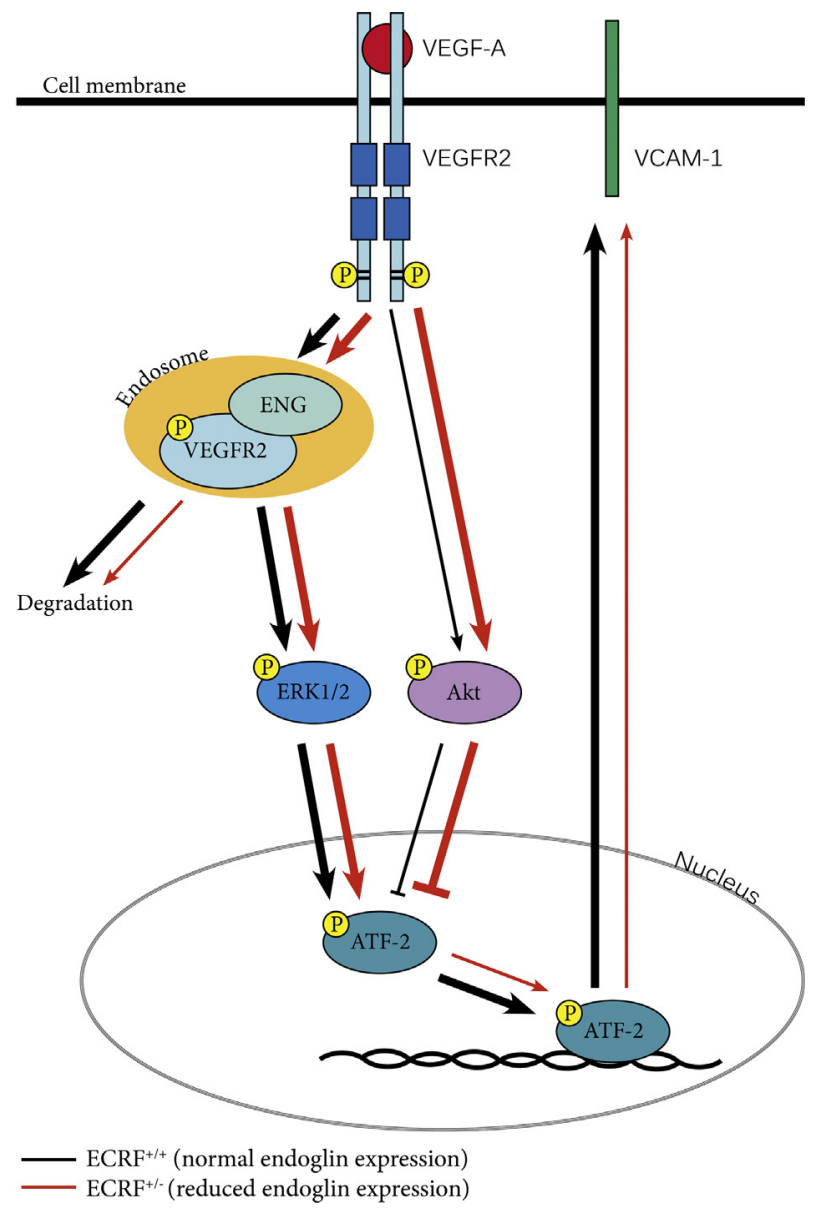

Figure 8 Schematic model of endoglin (ENG)-dependent endothelial cell activation on vascular endothelial growth factor (VEGF)-A stimulation. In endoglin-proficient cells $\left(\mathrm{ECRF}^{+/+}\right)$, VEGF-A drives endothelial cell activation via phosphorylation of VEGF receptor 2 (VEGFR2), which is then internalized in endosomes and, in turn, phosphorylates extracellular signal-regulated kinases 1 and 2 (ERK1/2). Activated pERK1/2 then translocates to the nucleus, where it phosphorylates activating transcription factor 2 (ATF-2), thereby up-regulating VCAM1 expression, increasing VCAM-1 levels at the cell surface (signaling depicted by the black lines). In cells with reduced endoglin expression $\left(\mathrm{ECRF}^{+/-}\right)$, VEGF-A stimulation causes increased Akt phosphorylation, which, in turn, inhibits ATF-2 activation, thereby resulting in reduced endothelial cell activation (signaling depicted by the red lines). The level of activation is indicated by the thickness of the line; a thicker line indicates stronger activation. Note: the residual endoglin levels in $\mathrm{ECRF}^{+/-}$cells allow ERK1/2 to still be activated.
Pan et al reported that, on stimulation with VEGF-A, both VEGFR2 and endoglin are internalized in endosomes and may be subsequently degraded, resulting in decreased endoglin protein levels. ${ }^{47}$ Our results support these findings, showing that endoglin protein levels are reduced in VEGFA-stimulated ECRF ${ }^{+/}$(Supplemental Figure S1, B and C). In contrast, in cells with reduced endoglin expression, VEGFR2 recycling is increased on stimulation with VEGFA. ${ }^{15}$ Because endoglin colocalizes with VEGFR2 in endosomes, this may also result in increased endoglin recycling to the plasma membrane. This would also explain why endoglin protein levels are unchanged in $\mathrm{ECRF}^{+/-}$on stimulation with VEGF-A (Supplemental Figure S1C).

In addition to reduced VEGF-A-induced endothelial cell activation, $\mathrm{ECRF}^{+/-}$also have reduced monocyte adhesion to VEGF-A-activated endothelial cells. During leukocyte extravasation, E-selectin is involved primarily in the rolling of leukocytes on the vessel's endothelial cell lining, whereas ICAM-1 and VCAM-1 arrest leukocytes at the endothelium. ${ }^{9}$ This suggests that endoglin facilitates monocyte adhesion by promoting endothelial cell activation. This hypothesis is supported by a recent study showing that the inflammationinduced transendothelial migration of leukocytes in the peritoneum and lungs is reduced in heterozygous endoglinknockout mice (which have an approximately 50\% reduction in endoglin levels) compared with wild-type mice. ${ }^{48}$ However, in their study, the authors found that endoglin binds to the integrin $\alpha 5 \beta 1$ on leukocytes via its arginylglycyl-aspartic acid (RGD) motif. These results suggest that endoglin increases the adhesion and transendothelial migration of inflammatory cells by at least two distinct mechanisms: a direct interaction with leukocytes and activating endothelial cells.

Patients with diabetic nephropathy are reported to have increased plasma levels of soluble VCAM-1 and soluble ICAM-1, 49,50 and these changes are correlated with albuminuria and vascular disease. ${ }^{50-52}$ In addition, E-selectin, P-selectin, and ICAM-1 levels are increased in the glomerular capillaries of patients with diabetic nephropathy, ${ }^{53}$ whereas VCAM-1 is not expressed. ${ }^{54}$ In contrast, and consistent with previous studies using diabetic animal models, ${ }^{17,39}$ increased levels of VCAM-1 protein were found in the glomerular capillaries of patients with diabetic nephropathy. This difference between previous studies and our results with respect to VCAM-1 expression in patients with diabetic nephropathy may be attributed to recent improvements in antibody specificity and/or signal amplification techniques. Moreover, in the patients with diabetic nephropathy, VCAM-1 was colocalized with endoglin in glomerular endothelial cells. Interestingly, although the levels of glomerular endoglin were similar between patients with diabetic nephropathy and nondiabetic controls, withinsample endoglin expression varied widely among glomeruli. This finding is in contrast with results obtained using our animal model, in which endoglin was up-regulated in all glomeruli, leading to higher endoglin expression in mice 
with diabetic nephropathy compared with control mice. This discrepancy in results may be explained-at least in part-by the presence of nodular glomerulosclerosis only in patient tissues (and not in mouse tissues); these nodules may have affected our measurements of endoglin. Our mixedmodel regression analysis of individual glomeruli in patients with diabetic nephropathy revealed a significant correlation between glomerular endoglin and glomerular VCAM-1 expression levels. This analysis, therefore, excludes the possibility that nodular glomerulosclerosis has a confounding effect. Taken together, these results suggest that endoglin may promote endothelial cell activation in patients, and endothelial cell activation is not always uniform within the kidney of a given patient.

In conclusion, our findings suggest that reducing endoglin function in patients at risk for diabetic nephropathy may be a viable strategy for inhibiting endothelial cell activation and monocyte adhesion, thereby preventing and/or reducing inflammation and the subsequent development of nephropathy.

\section{Acknowledgments}

We thank Dr. Luuk Hawinkels (Leiden University Medical Center, Leiden, the Netherlands) for providing immortalized human endothelial cells (ECRFs) that were transduced with a lentiviral vector expressing either an shRNA against endoglin $\left(\mathrm{ECRF}^{+/-}\right)$or a nontargeting control shRNA $\left(\mathrm{ECRF}^{+/+}\right)$.

P.B. designed and performed the experiments and wrote the manuscript; T.G., S.A.C.H., and M.Z. performed the experiments; R.W. performed the statistical analyses; J.A.B., M.S., and H.J.B. designed the experiments and provided technical support and conceptual advice; M.S. supervised the study; P.B. and M.S. are the guarantors of this work; all authors wrote the manuscript and approve the final version of the manuscript.

\section{Supplemental Data}

Supplemental material for this article can be found at https://doi.org/10.1016/j.ajpath.2018.08.005.

\section{References}

1. Atkins RC, Zimmet P: World Kidney Day 2010: diabetic kidney disease-act now or pay later. Am J Kidney Dis 2010, 55:205-208

2. Brownlee M: The pathobiology of diabetic complications: a unifying mechanism. Diabetes 2005, 54:1615-1625

3. Kim I, Moon SO, Kim SH, Kim HJ, Koh YS, Koh GY: Vascular endothelial growth factor expression of intercellular adhesion molecule 1 (ICAM-1), vascular cell adhesion molecule 1 (VCAM-1), and E-selectin through nuclear factor-kappa B activation in endothelial cells. J Biol Chem 2001, 276:7614-7620

4. Sato W, Kosugi T, Zhang L, Roncal CA, Heinig M, CampbellThompson M, Yuzawa Y, Atkinson MA, Grant MB, Croker BP, Nakagawa T: The pivotal role of VEGF on glomerular macrophage infiltration in advanced diabetic nephropathy. Lab Invest 2008, 88: 949-961
5. Lindenmeyer MT, Kretzler M, Boucherot A, Berra S, Yasuda Y Henger A, Eichinger F, Gaiser S, Schmid H, Rastaldi MP, Schrier RW, Schlondorff D, Cohen CD: Interstitial vascular rarefaction and reduced VEGF-A expression in human diabetic nephropathy. J Am Soc Nephrol 2007, 18:1765-1776

6. Liao JK: Linking endothelial dysfunction with endothelial cell activation. J Clin Invest 2013, 123:540-541

7. Page AV, Liles WC: Biomarkers of endothelial activation/dysfunction in infectious diseases. Virulence 2013, 4:507-516

8. Fearnley GW, Odell AF, Latham AM, Mughal NA, Bruns AF, Burgoyne NJ, Homer-Vanniasinkam S, Zachary IC, Hollstein MC, Wheatcroft SB, Ponnambalam S: VEGF-A isoforms differentially regulate ATF-2-dependent VCAM-1 gene expression and endothelial-leukocyte interactions. Mol Biol Cell 2014, 25:2509-2521

9. Vestweber D: How leukocytes cross the vascular endothelium. Nat Rev Immunol 2015, 15:692-704

10. Li DY, Sorensen LK, Brooke BS, Urness LD, Davis EC, Taylor DG, Boak BB, Wendel DP: Defective angiogenesis in mice lacking endoglin. Science 1999, 284:1534-1537

11. Arthur HM, Ure J, Smith AJ, Renforth G, Wilson DI, Torsney E, Charlton R, Parums DV, Jowett T, Marchuk DA, Burn J, Diamond AG: Endoglin, an ancillary TGFbeta receptor, is required for extraembryonic angiogenesis and plays a key role in heart development. Dev Biol 2000, 217:42-53

12. Jonker L, Arthur HM: Endoglin expression in early development is associated with vasculogenesis and angiogenesis. Mech Dev 2002, 110:193-196

13. Botella LM, Sanchez-Elsner T, Sanz-Rodriguez F, Kojima S, Shimada J, Guerrero-Esteo M, Cooreman MP, Ratziu V, Langa C, Vary CP, Ramirez JR, Friedman S, Bernabeu C: Transcriptional activation of endoglin and transforming growth factor-beta signaling components by cooperative interaction between Sp1 and KLF6: their potential role in the response to vascular injury. Blood 2002, 100: $4001-4010$

14. Torsney E, Charlton R, Parums D, Collis M, Arthur HM: Inducible expression of human endoglin during inflammation and wound healing in vivo. Inflamm Res 2002, 51:464-470

15. Jin Y, Muhl L, Burmakin M, Wang Y, Duchez AC, Betsholtz C, Arthur HM, Jakobsson L: Endoglin prevents vascular malformation by regulating flow-induced cell migration and specification through VEGFR2 signalling. Nat Cell Biol 2017, 19:639-652

16. Kim AH, Khursigara G, Sun X, Franke TF, Chao MV: Akt phosphorylates and negatively regulates apoptosis signal-regulating kinase 1. Mol Cell Biol 2001, 21:893-901

17. Bus P, Scharpfenecker M, Van Der Wilk P, Wolterbeek R, Bruijn JA, Baelde HJ: The VEGF-A inhibitor sFLT-1 improves renal function by reducing endothelial activation and inflammation in a mouse model of type 1 diabetes. Diabetologia 2017, 60:1813-1821

18. Deeds MC, Anderson JM, Armstrong AS, Gastineau DA, Hiddinga HJ, Jahangir A, Eberhardt NL, Kudva YC: Single dose streptozotocin-induced diabetes: considerations for study design in islet transplantation models. Lab Anim 2011, 45:131-140

19. Gurley SB, Clare SE, Snow KP, Hu A, Meyer TW, Coffman TM: Impact of genetic background on nephropathy in diabetic mice. Am J Physiol Renal Physiol 2006, 290:F214-F222

20. Fontijn R, Hop C, Brinkman HJ, Slater R, Westerveld A, van Mourik JA, Pannekoek H: Maintenance of vascular endothelial cellspecific properties after immortalization with an amphotrophic replication-deficient retrovirus containing human papilloma virus 16 E6/E7 DNA. Exp Cell Res 1995, 216:199-207

21. Gerber HP, McMurtrey A, Kowalski J, Yan M, Keyt BA, Dixit V, Ferrara N: Vascular endothelial growth factor regulates endothelial cell survival through the phosphatidylinositol 3'-kinase/Akt signal transduction pathway. Requirement for Flk-1/KDR activation. J Biol Chem 1998, 273:30336-30343

22. Baelde HJ, Eikmans M, Lappin DW, Doran PP, Hohenadel D, Brinkkoetter PT, van der Woude FJ, Waldherr R, Rabelink TJ, de 
Heer E, Bruijn JA: Reduction of VEGF-A and CTGF expression in diabetic nephropathy is associated with podocyte loss. Kidney Int 2007, 71:637-645

23. Rodriguez-Barbero A, Obreo J, Eleno N, Rodriguez-Pena A, Duwel A, Jerkic M, Sanchez-Rodriguez A, Bernabeu C, LopezNovoa JM: Endoglin expression in human and rat mesangial cells and its upregulation by TGF-beta1. Biochem Biophys Res Commun 2001, 282:142-147

24. Essawy M, Soylemezoglu O, Muchaneta-Kubara EC, Shortland J, Brown CB, el Nahas AM: Myofibroblasts and the progression of diabetic nephropathy. Nephrol Dial Transplant 1997, 12:43-50

25. Ichimura K, Kurihara H, Sakai T: Involvement of mesangial cells expressing alpha-smooth muscle actin during restorative glomerular remodeling in Thy-1.1 nephritis. J Histochem Cytochem 2006, 54: $1291-1301$

26. Johnson RJ, Iida H, Alpers CE, Majesky MW, Schwartz SM, Pritzi P, Gordon K, Gown AM: Expression of smooth muscle cell phenotype by rat mesangial cells in immune complex nephritis. Alpha-smooth muscle actin is a marker of mesangial cell proliferation. J Clin Invest 1991, 87:847-858

27. Gonlusen G, Ergin M, Paydas S, Tunali N: The expression of cytoskeletal proteins (alpha-SMA, vimentin, desmin) in kidney tissue: a comparison of fetal, normal kidneys, and glomerulonephritis. Int Urol Nephrol 2001, 33:299-305

28. Irigoyen JP, Munoz-Canoves P, Montero L, Koziczak M, Nagamine Y: The plasminogen activator system: biology and regulation. Cell Mol Life Sci 1999, 56:104-132

29. Grotendorst GR, Okochi H, Hayashi N: A novel transforming growth factor beta response element controls the expression of the connective tissue growth factor gene. Cell Growth Differ 1996, 7: 469-480

30. Blanco FJ, Bernabeu C: The splicing factor SRSF1 as a marker for endothelial senescence. Front Physiol 2012, 3:54

31. Quagliaro L, Piconi L, Assaloni R, Da Ros R, Maier A, Zuodar G, Ceriello A: Intermittent high glucose enhances ICAM-1, VCAM-1 and E-selectin expression in human umbilical vein endothelial cells in culture: the distinct role of protein kinase $\mathrm{C}$ and mitochondrial superoxide production. Atherosclerosis 2005, 183:259-267

32. Basta G, Lazzerini G, Massaro M, Simoncini T, Tanganelli P, Fu C, Kislinger T, Stern DM, Schmidt AM, De Caterina R: Advanced glycation end products activate endothelium through signal-transduction receptor RAGE: a mechanism for amplification of inflammatory responses. Circulation 2002, 105:816-822

33. Onozato ML, Tojo A, Goto A, Fujita T: Radical scavenging effect of gliclazide in diabetic rats fed with a high cholesterol diet. Kidney Int 2004, 65:951-960

34. Hattori M, Nikolic-Paterson DJ, Miyazaki K, Isbel NM, Lan HY, Atkins RC, Kawaguchi H, Ito K: Mechanisms of glomerular macrophage infiltration in lipid-induced renal injury. Kidney Int Suppl 1999, 71:S47-S50

35. Okouchi M, Okayama N, Shimizu M, Omi H, Fukutomi T, Itoh M: High insulin exacerbates neutrophil-endothelial cell adhesion through endothelial surface expression of intercellular adhesion molecule-1 via activation of protein kinase $\mathrm{C}$ and mitogen-activated protein kinase. Diabetologia 2002, 45:556-559

36. Griffin GK, Newton G, Tarrio ML, Bu DX, Maganto-Garcia E, Azcutia V, Alcaide P, Grabie N, Luscinskas FW, Croce KJ, Lichtman AH: IL-17 and TNF-alpha sustain neutrophil recruitment during inflammation through synergistic effects on endothelial activation. J Immunol 2012, 188:6287-6299

37. Awad AS, You H, Gao T, Cooper TK, Nedospasov SA, Vacher J, Wilkinson PF, Farrell FX, Brian Reeves W: Macrophage-derived tumor necrosis factor-alpha mediates diabetic renal injury. Kidney Int $2015,88: 722-733$
38. Faulkner J, Pye C, Al-Shabrawey M, Elmarakby AA: Inhibition of 12/15-lipoxygenase reduces renal inflammation and injury in streptozotocin-induced diabetic mice. J Diabetes Metab 2015, 6:555

39. Sassy-Prigent C, Heudes D, Mandet C, Belair MF, Michel O, Perdereau B, Bariety J, Bruneval P: Early glomerular macrophage recruitment in streptozotocin-induced diabetic rats. Diabetes 2000, 49:466-475

40. Chow FY, Nikolic-Paterson DJ, Ozols E, Atkins RC, Tesch GH: Intercellular adhesion molecule-1 deficiency is protective against nephropathy in type 2 diabetic db/db mice. J Am Soc Nephrol 2005, 16:1711-1722

41. Okada S, Shikata K, Matsuda M, Ogawa D, Usui H, Kido Y, Nagase R, Wada J, Shikata Y, Makino H: Intercellular adhesion molecule-1-deficient mice are resistant against renal injury after induction of diabetes. Diabetes 2003, 52:2586-2593

42. Scharpfenecker M, Floot B, Russell NS, Ten Dijke P, Stewart FA: Endoglin haploinsufficiency reduces radiation-induced fibrosis and telangiectasia formation in mouse kidneys. Radiother Oncol 2009, 92: 484-491

43. Docherty NG, Lopez-Novoa JM, Arevalo M, Duwel A, RodriguezPena A, Perez-Barriocanal F, Bernabeu C, Eleno N: Endoglin regulates renal ischaemia-reperfusion injury. Nephrol Dial Transplant 2006, 21:2106-2119

44. Oujo B, Munoz-Felix JM, Arevalo M, Nunez-Gomez E, PerezRoque L, Pericacho M, Gonzalez-Nunez M, Langa C, MartinezSalgado C, Perez-Barriocanal F, Bernabeu C, Lopez-Novoa JM: LEndoglin overexpression increases renal fibrosis after unilateral ureteral obstruction. PLoS One 2014, 9:e110365

45. Min JK, Lee YM, Kim JH, Kim YM, Kim SW, Lee SY, Gho YS, Oh GT, Kwon YG: Hepatocyte growth factor suppresses vascular endothelial growth factor-induced expression of endothelial ICAM-1 and VCAM-1 by inhibiting the nuclear factor-kappaB pathway. Circ Res 2005, 96:300-307

46. Simons M: An inside view: VEGF receptor trafficking and signaling. Physiology (Bethesda) 2012, 27:213-222

47. Pan CC, Kumar S, Shah N, Hoyt DG, Hawinkels LJ, Mythreye K, Lee NY: Src-mediated post-translational regulation of endoglin stability and function is critical for angiogenesis. J Biol Chem 2014, 289:25486-25496

48. Rossi E, Sanz-Rodriguez F, Eleno N, Duwell A, Blanco FJ, Langa C, Botella LM, Cabanas C, Lopez-Novoa JM, Bernabeu C: Endothelial endoglin is involved in inflammation: role in leukocyte adhesion and transmigration. Blood 2013, 121:403-415

49. Clausen P, Jacobsen P, Rossing K, Jensen JS, Parving HH, FeldtRasmussen B: Plasma concentrations of VCAM-1 and ICAM-1 are elevated in patients with Type 1 diabetes mellitus with microalbuminuria and overt nephropathy. Diabet Med 2000, 17:644-649

50. Rubio-Guerra AF, Vargas-Robles H, Lozano Nuevo JJ, EscalanteAcosta BA: Correlation between circulating adhesion molecule levels and albuminuria in type-2 diabetic hypertensive patients. Kidney Blood Press Res 2009, 32:106-109

51. Jude EB, Douglas JT, Anderson SG, Young MJ, Boulton AJ: Circulating cellular adhesion molecules ICAM-1, VCAM-1, P- and E-selectin in the prediction of cardiovascular disease in diabetes mellitus. Eur J Intern Med 2002, 13:185-189

52. Koga M, Otsuki M, Kubo M, Hashimoto J, Kasayama S: Relationship between circulating vascular cell adhesion molecule-1 and microvascular complications in type 2 diabetes mellitus. Diabet Med 1998, 15:661-667

53. Hirata K, Shikata K, Matsuda M, Akiyama K, Sugimoto H, Kushiro M, Makino H: Increased expression of selectins in kidneys of patients with diabetic nephropathy. Diabetologia 1998, 41:185-192

54. Seron D, Cameron JS, Haskard DO: Expression of VCAM-1 in the normal and diseased kidney. Nephrol Dial Transplant 1991, 6:917-922 